\title{
Components of the Endocannabinoid System and Effects of Cannabinoids Against Bone Diseases: A Mini-Review
}

\author{
Yuqi $\mathrm{Xin}^{\dagger}$, Anqun $\mathrm{Tang}^{\dagger}$, Shuting Pan and Jie Zhang * \\ Department of Oral and Maxillofacial Surgery, The First Affiliated Hospital of Nanchang University, Nanchang, China
}

OPEN ACCESS

Edited by:

Cristoforo Pomara,

University of Catania, Italy

Reviewed by:

Paolo Tucci,

University of Foggia, Italy

Chawon Yun,

Northwestern University,

United States

${ }^{*}$ Correspondence:

Jie Zhang

ndyfy02134@ncu.edu.cn

zhjprs@163.com

${ }^{t}$ These authors have contributed equally to this work and share first

authorship

Specialty section:

This article was submitted to Experimental Pharmacology and Drug

Discovery,

a section of the journal

Frontiers in Pharmacology

Received: 13 October 2021

Accepted: 23 December 2021

Published: 19 January 2022

Citation:

Xin Y, Tang A, Pan S and Zhang

(2022) Components of the

Endocannabinoid System and Effects

of Cannabinoids Against Bone

Diseases: A Mini-Review.

Front. Pharmacol. 12:793750.

doi: 10.3389/fphar.2021.793750
Background: The endocannabinoid system (ECS) is involved in multiple physiological processes, including appetite regulation, pain perception, motor function development, and immune response regulation. Cannabinoids have been approved for the clinical treatment of nausea and vomiting caused by cytostatic therapy or cancer chemotherapy, loss of appetite in HIV/AIDS-associated cachexia, refractory spasms induced by multiple sclerosis, chronic pain, and urinary incontinence.

Methods: Check out the research on ECS and bone diseases in the past 20 years.

Results: Many studies have demonstrated that endocannabinoids (eCBs) and cannabinoid receptors (CBRs) are expressed in bone and synovial tissues, playing important roles in bone metabolism. Preclinical studies using cannabis-based therapies in animal models have shown that cannabinoids (CBs) can alleviate the development of osteoarthritis $(\mathrm{OA})$, prevent osteoporosis $(\mathrm{OP})$, reduce cancer-induced osteolytic destruction, and improve fracture healing, highlighting the therapeutic potential of CBs for human bone diseases.

Conclusions: The present review summarizes various components of the ECS in bone diseases and their potential as a therapeutic target.

Keywords: cannabinoids, bone loss, osteoporosis, osteoarthritis, bone tumor, bone fractures

\section{INTRODUCTION}

Cannabis Sativa has been used medicinally and recreationally for thousands of years. As early as in 2600 B.C., cannabis was already used in treating malaria, constipation, pain and dysmenorrhoea in China (Mechoulam, 1986; Grinspoon, 1993). In the late 19th century, European people began using cannabis to treat pain, muscle spasms, asthma, insomnia, depression and anorexia. However, it was not until 1964 that its major active chemical component delta-9-tetrahydrocannabinol (THC), also known as dronabinol, was discovered (Gaoni and Mechoulam, 1964). Nearly 30 years later, a specific cannabinoid receptor (CBR) was identified as the target of THC (Devane et al., 1988; Munro et al.,

\footnotetext{
Abbreviations: ECS, The endocannabinoid system; eCB, endocannabinoid; $\mathrm{CBR}$, cannabinoid receptor; $\mathrm{CB}$, cannabinoid; OA, osteoarthritis; OP, osteoporosis; THC, delta-9-tetrahydrocannabinol; AEA, anandamide; 2-AG, 2-arachidonoylglycerol; OP, osteoporosis; GPR, G-protein coupled receptors; TRPV, transient receptor potential vanilloids; PPAR, peroxisome proliferatoractivated receptor; OCs, osteoclasts; OB, osteoblasts; FAAH, fatty acid amide hydrolase; MAGL, monoacylglycerol lipase; CBD, cannabisol; TNF, tumor necrosis factor; NF-B, nuclear factor-B; LPS, lipopolysaccharide; MMPs, matrix metalloproteinases; RA, rheumatoid arthritis.
} 
1993). In 1992, Devane et al. discovered the first endocannabinoid (eCB) $\mathrm{N}$-arachidonoylethanolamine or anandamide (AEA) as the endogenous ligand of CBR in the pig brain (Devane et al., 1992) Subsequently in 1995, the second eCB 2-arachidonoylglycerol (2AG) was also discovered (Mechoulam et al., 1995). With the discovery of endocannabinoids, a great number of studies have investigated the physiological functions of the endocannabinoid system (ECS).

The ECS is recognized to play a significant role in regulating a variety of physiological processes, including appetite control, pain perception, and immune regulation (Idris and Ralston, 2010; Robson, 2014). Marinol (dronabinol), a cannabinoid receptor 1(CB1) agonist, has been approved in the United States of America (USA) for the clinical treatment of nausea and vomiting, and anorexia caused by cytostasis or AIDS. Nabilone has also been approved in the United Kingdom (UK) for the treatment of chemotherapy-induced adverse effects in cancer patients. A new CB drug (sativex) has also be approved in Germany for the treatment of intractable muscle spasm caused by multiple sclerosis (Grotenhermen and Müller-Vahl, 2012).

Several research groups have reported ECS expression in bone and synovial tissues and its important role in bone metabolism (Carnovali et al., 2016; Ehrenkranz and Levine, 2019; Dou et al., 2020). Preclinical studies in animal models demonstrated that CBs could alleviate the development of arthritis, prevent osteoporosis (OP), inhibit bone tumor cell proliferation, reduce bone cancer pain and improve fracture healing (Smoum et al., 2015; Carnovali et al., 2016; Frei et al., 2016; Marino et al., 2019; Yan et al., 2019). In this regard, recent progress in the application of CBs in bone diseases has been reviewed, with the expectation to provide a new direction for the clinical treatment of bone diseases. In this article, we will discuss the potential therapeutic effects of $\mathrm{CBs}$ for the treatment of patients with bone diseases.

\section{CB EXPRESSION IN BONE AND JOINT TISSUES}

The ECS consist of endogenous cannabinoid ligands (endocannabinoids, eCBs), their receptors, and the gene enzymes involved in their synthesis and degradation (McPartland et al., 2006; Pertwee et al., 2010). Arachidonoylethanolamine (AEA) and 2-Arachidonoylglycerol (2-AG) are two firstly identified and most studied eCBs, which are believed to be involved in a wide range of physiological processes including appetite stimulation, pain modulation and energy expenditure (Di Marzo and Petrosino, 2007). Cannabinoid receptor 1 (CB1) and 2 (CB2) are the characterised cannabinoid receptors, to which AEA and 2-AG bind in the nanomolar range. 2-AG is considered a full agonist, and AEA is considered a partial agonist (Pertwee and Ross, 2002). Other receptors known for eCBs include G-protein coupled receptors (GPR55 and GPR119), transient receptor potential vanilloids (TRPV1 and TRPV4), peroxisome proliferator-activated receptors (PPARa and PPAR $\gamma$ ), and various ion channels (Pertwee, 2010).
The ECS exists in most mammalian organs and tissues, playing primarily important roles in the nervous and immune systems (Joshi and Onaivi, 2019; Silver Robert, 2019). ECBs and their receptors are also expressed in the bone (Rossi et al., 2009; Whyte et al., 2009). CB1, CB2 and TRPV1 have been identified in human osteoclasts (OCs) and GPR55, and found to be expressed in both human osteoblasts (OBs) and OCs (Rossi et al., 2009; Whyte et al., 2009). Mouse OBs and OCs express CB1, CB2, GPR55 and TRPV1 (Idris et al., 2005; Ofek et al., 2006; Idris et al., 2009; Whyte et al., 2009; Idris et al., 2010). Studies of the innervation of the mouse bone have shown that CB1 and TRPV1 are expressed in sympathetic nerve fibers (Ghilardi et al., 2005; Tam et al., 2006). AEA and 2-AG are responsible for most of the pharmacological effects associated with CBRs in mammalian cells (Pertwee, 2005). Jiang $S$ et al. discovered AEA and 2-AG are produced in bone marrow (Bab et al., 2008; Tam et al., 2008; Jiang et al., 2010). AEA and 2-AG are detectable in human OC- and OB-like cells in vitro (Rossi et al., 2009; Whyte et al., 2012). Rossi et al. (2009) reported that cultured human OCs produced 2-AG and a certain amount of AEA in vitro, and the level of eCBs increased when the culture was treated with URB597, a fatty acid amide hydrolase (FAAH) inhibitor. Whyte et al. (2012) reported that differentiation of human OCs was related to the increased AEA level and decreased 2AG level. These observations suggest that AEA and 2-AG may be produced by bone cells and within the cultured bone (Tam et al., 2008; Maccarrone et al., 2015). The enzyme diacylglycerol lipases $a$ and $\beta$ and NAPE-phospholipase $\mathrm{D}$, which are required for 2$A G$ and AEA synthesis respectively, are also expressed in OBs and OCs (Tam et al., 2008; Rossi et al., 2009). Similarly, the degradation enzymes FAAH and monoacylglycerol lipase (MAGL) have been found in human OCs and mouse OBs (Hutchins et al., 2011; Rossi et al., 2011). The role of cannabinoid receptor ligands in regulating osteoclasts, osteoblasts and adipocytes in vitro and in vivo are shown in Table 1.

The ECS is also expressed in synovial tissues of joints. Richardson et al. (2008) reported that CB1 and CB2 receptors were expressed in synovial biopsies of human osteoarthritis (OA) and rheumatoid arthritis (RA) by Western Blot detection, and played a role in regulating physiological functions. Further evidence showed that AEA and 2-AG could be detected in synovial fluid from OA and RA patients but not in synovial fluid from normal subjects. Dunn et al. (2016) reported that a wide range of CBRs including $\mathrm{CB} 1, \mathrm{CB} 2$, GPR55, PPARaand PPAR $\gamma$ were expressed in chondrocytes of OA joints, and even in degenerate tissues.

\section{CANNABINOIDS AFFECT BONE DISEASES}

\section{Osteoporosis}

OBs are known to synthesize bone cells to produce AEA and 2AG, and express CB1 receptors on their surfaces (Tam et al., 2008; Maccarrone et al., 2015). Activation of CB1 in OBs inhibits the release of norepinephrine, which to some extent suppresses the process of bone formation, i.e., CB1 activation inhibits bone 
TABLE 1 The role of cannabinoid receptor ligands in regulating osteoclasts, osteoblasts, and adipocytes in vitro and in vivo.

\begin{tabular}{|c|c|c|c|c|c|c|}
\hline & \multirow[t]{3}{*}{ Ligand } & \multirow[t]{3}{*}{ Receptor } & \multicolumn{4}{|c|}{ Bone metabolism } \\
\hline & & & Oc & Oc & Ob & Ac \\
\hline & & & Number & Activity & Number & Number \\
\hline \multirow[t]{12}{*}{ Agonists } & AEA & CB1/CB2/GPR55/TRPV1 & $\uparrow$ & $\uparrow$ & $\uparrow$ & - \\
\hline & $2-A G$ & CB1/CB2/GPR55 & $\uparrow$ & $\uparrow$ & $\uparrow$ & - \\
\hline & $\Delta 9-\mathrm{THC}$ & $\mathrm{CB} 1 / \mathrm{CB} 2$ & - & - & - & - \\
\hline & CP55,940 & CB1/CB2 & $\uparrow \downarrow$ & $\uparrow$ & $\uparrow$ & $\downarrow$ \\
\hline & WIN55,212 & CB1 & - & - & $\uparrow$ & - \\
\hline & HU308 & CB2 & $\uparrow \downarrow \downarrow$ & - & $\uparrow \uparrow$ & $\downarrow$ \\
\hline & JWH133 & CB2 & $\uparrow$ & $\uparrow$ & $\uparrow$ & $\downarrow$ \\
\hline & JWH139 & CB2 & - & - & - & - \\
\hline & JWH015 & CB2 & - & $\uparrow$ & $\uparrow$ & $\downarrow$ \\
\hline & AM1241 & CB2 & - & - & - & - \\
\hline & Lysophosphatidyl inositol & GPR55 & $\downarrow$ & $\uparrow$ & - & - \\
\hline & $0-1602$ & GPR55 & $\downarrow$ & $\uparrow$ & $\uparrow$ & - \\
\hline \multirow[t]{5}{*}{ Antagonists } & AM630 & CB2>CB1/GPR55 & $\downarrow \downarrow \uparrow$ & $\downarrow$ & $\downarrow$ & - \\
\hline & SR144528 & $\mathrm{CB} 2>\mathrm{CB} 1$ & $\downarrow$ & $\downarrow$ & $\downarrow$ & - \\
\hline & AM251 & CB1>CB2/GPR55 & $\downarrow \downarrow \uparrow$ & $\downarrow$ & $\downarrow$ & $\uparrow$ \\
\hline & SR141716A & $\mathrm{CB} 1>\mathrm{CB} 2$ & $\downarrow \downarrow$ & $\downarrow$ & $\downarrow$ & - \\
\hline & Cannabidiol & GPR55 & $\uparrow$ & $\downarrow \downarrow$ & - & - \\
\hline
\end{tabular}

Abbreviations: CB1, cannabinoid type 1 receptor; CB2, cannabinoid type 2 receptor; GPR55, G protein-coupled receptor 55; TRPV1, transient receptor potential vanilloid type 1. Oc., osteoclast; Ob., osteolblast; Ac., adipocyte. $\uparrow$, increase; $\downarrow$, decrease; -, non tested. Black and red arrows denote in vitro and in vivo data, respectively.

production (Tam et al., 2006). In addition, OCs also express AEA and 2-AG, but with CB2 receptors instead of CB1 (Whyte et al., 2012). CB2 activation in OCs suppresses osteolysis activity, thereby preserving the bone tissue (Whyte et al., 2012). This effect proves highly beneficial to balancing the relationship between hyperactive OCs and inactive OBs in OP, leading to increased bone resorption without compensatory bone formation. These findings support that the ECS is the main regulatory system of the bone. Although norepinephrine is directly responsible for the activities of OCs and OBs, the level of norepinephrine is mainly mediated both by the ECS expressed in the sympathetic nervous system and that expressed in the bone tissue itself.

CBs have been shown to regulate bone formation, bone loss and bone turnover. The ECS system is an important regulator of bone mass. CBR agonists promote differentiation of mouse mesenchymal stem cells (MSCs) into OBs (Zhang et al., 2019). Idris et al. (Hutchins et al., 2011) reported that CB1 receptor inactivation increased bone mass and prevented bone loss due to ovariectomy, an in vivo model of OP in 2005. In addition, Rossi et al. reported that $\mathrm{CB} 2$ receptors had an anti-osteoporosis function (Rossi et al., 2019). CB2 receptor agonists increased bone mass by enhancing the number and activity of OBs, inhibiting the proliferation of OCs, and stimulating fibroblastic colony formation by myeloid cells (Ofek et al., 2006). Furthermore, CB2 receptor regulates bone loss also involving the regulation of osteoclast function (Sophocleous et al., 2017). Therefore, $\mathrm{CB} 2$ provides a molecular target for the diagnosis and treatment of OP.

GPR55 was expressed in human and mouse OCs and OBs. In contrast to the bone turnover function of $\mathrm{CB} 1$ and $\mathrm{CB} 2$ receptors, GPR55 inhibited OC formation but stimulates OB function. Histomorphometric and microcomputed tomography analysis of the long bones in male GPR55 (-/-) mice revealed that the number of OCs was increased, but the volume and thickness of the trabecular bone was increased significantly with no cartilage resorption observed, a possibility is that osteoclast numbers were increased, but osteoclast function was impaired (Whyte et al., 2009). Therefore, GPR55 receptor agonists promote bone loss. A recent study of OCs from patients with OP suggested that GPR55 desensitization by FAAs or its enhanced transport, and TRPV1 agonist-induced overexpression of CB2 receptor might be critical to reduce calciumentry into OCs, which could lead to over-activation of cells and increase bone resorption and bone loss. TRPV1 agonistsCB together with $\mathrm{CB} 2$ agonists were reported useful for the treatment of OP (Rossi et al., 2011). These results indicate that CBRs agonists could be used for the prevention and treatment of OP.

\section{Osteoarthritis}

$\mathrm{OA}$ is characterized by degeneration of the articular cartilage, which is mediated by complex interactions of proinflammatory cytokines including IL-1, inflammatory mediators and proteases. CBs have been shown to prevent IL-1-induced matrix breakdown of collagen and proteoglycan, suggesting that they may play an important role in cartilage protection (Mbvundula et al., 2006). CBs exert their effects through several CBRs, and therefore it is important to identify the key CBs and CBRs involved in cartilage protection. CBRs are expressed in synovial tissues and osteoarthritic articular chondrocytes and produce important physiological effects such as reducing arthritis inflammation and alleviating arthritis-associated pain symptoms (Mbvundula et al., 2006; Guidetti et al., 2014). Malfait et al. (2000) described the effect of a high potency dimeric cannabinoid, named cannabisol (CBD), in a mouse arthritis model and found that CBD had immunosuppressive and anti-inflammatory activities 
and could improve the symptoms of arthritis in a murine collagen-induced arthritis model by both intraperitoneal and oral administration methods. They also found that CBD could reduce joint damage. The in vitro effects of $\mathrm{CBD}$ included dosedependent inhibition of lymphocyte proliferation, both mitogenstimulated and antigen-specific, and reactive oxygen burst triggered by peritoneal granulocytes blocking zymosan. It was also found that CBD administration could block the increase of serum tumor necrosis factor (TNF) induced by lipopolysaccharide in C57/BL mice. Sumariwalla et al. (2004) used a synthetic $\mathrm{CB}$ (HU-320) in a similar experiment and found that this novel synthetic CB HU-320 could be used to treat arthritis in mice due to its strong anti-inflammatory and immunosuppressive properties without showing psychoactive effects. HU-320 inhibited the production of tumor necrosis factor (TNF) and reactive oxygen intermediates (ROIs) from mouse macrophages and RAW 264.7 cells respectively, as well as the increased serum TNF level following endotoxin attack.

Oversecretion of proinflammatory cytokines from OBs plays an essential role in the development of OA (Liu et al., 2014; Sun et al., 2014), and high levels of pro-inflammatory factors in bones and joints induce pain, cartilage loss, and even joint dysfunction (Yang et al., 2013; Karsdal et al., 2014). Therefore, reducing the release of pro-inflammatory cytokines from OBs is an effective therapy for OA. Yang et al. (2015) have reported that THC inhibited the release of pro-inflammatory cytokines, including TNF- $\alpha$, IL-1, IL-6, and IL-8, decreased nuclear factor-B (NF-B) expression, and inhibited the upregulation of cofilin-1 protein (a cytoskeleton protein involved in inflammation of $\mathrm{OA}$ of lipopolysaccharide (LPS)-stimulated MG-63 cells. The administration of the $\mathrm{CB} 2$ receptor antagonist or the $\mathrm{CB} 2$ siRNA partially abolished the above-mentioned THC-induced anti-inflammatory effect. In addition, overexpression of cofilin-1 significantly reversed the THC-induced anti-inflammatory effect in MG-63 cells. These results indicate that CB2 is involved in the anti-inflammation induced by THC in LPS-stimulated MG-63 cells, and suggest that the anti-inflammatory effect may be mediated by cofilin-1 (Yang et al., 2015).

Cannabinoids exert chondroprotective effects and are useful for OA treatment (Dunn et al., 2012). Dunn et al. (Dunn et al., 2016) designed CBs to bind to their receptors and found that they inhibited the catabolic and pain pathways within the arthritic joint without causing psychoactive effects, suggesting a therapeutic potential for arthritis. Sophocleous et al. (2015) reported that $\mathrm{CB} 2$-selective agonist $\mathrm{HU} 308$ reduced the severity of total knee joint OA following surgical destabilization of the medial meniscus (DMM) in wide type mice. When compared with wild-type chondrocytes, cultured articular chondrocytes from $\mathrm{CB} 2$ deletion $\left(\mathrm{CB} 2^{-/-}\right)$mice produced less proteoglycans in vitro, indicated that the $\mathrm{CB} 2$ pathway played a role in the pathophysiology of murine OA, and that the pharmacological activity of $\mathrm{CB} 2$ had a protective effect against OA.

There is increasing evidence that the ECS, especially CB2, also plays an important role in the pathophysiology of rheumatoid arthritis (RA) (Lowin et al., 2019). Gui et al. (2014) reported that many members of the ECS inhibit synovial inflammation, hyperplasia, and cartilage destruction in RA. In particular, activation of CB2 may relieve RA by inhibiting the production of autoantibodies, proinflammatory cytokines, and matrix metalloproteinases (MMPs), as well as bone erosion, $\mathrm{T}$ cells mediated immune response, and the proliferation of FLSs (Gui et al., 2014).

CBs can also reduce the loss of thealveolar bone (Ossola et al., 2016). Ossola et al. have demonstrated that CB-2 receptor was expressed in OBs and OCs to promote bone metabolism. And the results of their studies in rat models showed that alveolar bone loss was greatly attenuated by the use of CB-2 receptor agonist HU-308 in LPS-induced periodontitis and as such demonstrated anti-inflammatroy, osteoprotective, prohomeostatic effects (Ossola et al., 2016).

CBs can not only reduce the inflammation of arthritis but relieve the pain symptoms of arthritis. The termination of endocannabinoid activity is achieved by cellular uptake, followed by intracellular hydrolysis by fatty acid amide hydrolase (FAAH) (Schuelert et al., 2011). Schuelert et al. (2011) indicated local injection of FAAH inhibitor URB597 into the OA knee joints reduced mechanical nociception and pain in two OA rodent models, and this response was eliminated by $\mathrm{CB} 1$ receptor antagonists, indicating that CB1 receptor could be used as an arthritic pain treatment target.

\section{Bone Tumors}

Several studies have demonstrated the positive effects of the ECS in the treatment of cancer. CBRs can inhibit tumor cell proliferation, reduce tumor cell invasion, cause tumor regression and prevent tumor metastasis. For example, Qamri et al. (2009) reported that synthetic CBR agonists inhibited tumor growth and metastasis of breast cancer. Preet et al. (2008) indicated that delta9-Tetrahydrocannabinol inhibited lung cancer cell migration in vitro as well as its growth and metastasis in vivo. Gustafsson et al. (2008) showed that therapeutic options using ABR ligands had the efficacy of reducing tumor burden in malignant lymphoma overexpressing $\mathrm{CB} 1$ and $\mathrm{CB} 2$. However, the role of $\mathrm{CBs}$ in bone metastasis remains to be studied.

There have been many studies concerning the use of the ECS in the treatment of primary bone tumors. For tumor cells, ECS can affect their growth, movement, invasion, spread, and colonization of distant organs. It was found that CB2 was modulated in the genetic and phrenological processes, thus affecting bone cell activity in remodeling in both healthy individuals and patients (Di Marzo, 2008; Marino and Idris, 2017). Furthermore, Niu et al. (2015) have demonstrated that the synthetic cannabinoid CB receptor agonist WIN-55,212-2 has therapeutic effect on the MG-63 human osteosarcoma cell line. WIN-55,212-2 inhibit migration, invasion and angiogenic activity of this cell line. The mechanism of this inhibition is associated with the downregulation of the Notch-1 and MMP-2 signaling pathways, which are known as important pathways associated with cell proliferation and apotosis as well as degradation of extra-cellular matrix, the key to tumor invasion. High level of MMP-2 is considered a key indicator 
TABLE 2 | The role of cannabinoid receptor ligands in regulating tumor cells and bone diseases in vitro and in vivo.

\begin{tabular}{|c|c|c|c|c|c|}
\hline & \multirow[t]{2}{*}{ Ligand } & \multirow[t]{2}{*}{ Receptor } & \multicolumn{3}{|c|}{ Bone tumor } \\
\hline & & & Tm.Growth & Osteolysis & Pain \\
\hline \multirow[t]{12}{*}{ Agonists } & AEA & CB1/CB2/GPR55/TRPV1 & $\downarrow \downarrow$ & - & $\downarrow$ \\
\hline & 2-AG & CB1/CB2/GPR55 & $\downarrow$ & $\downarrow$ & - \\
\hline & $\Delta 9-\mathrm{THC}$ & $\mathrm{CB} 1 / \mathrm{CB} 2$ & $\downarrow \downarrow \uparrow \uparrow$ & - & $\downarrow$ \\
\hline & CP55,940 & $\mathrm{CB} 1 / \mathrm{CB} 2$ & $\downarrow$ & - & \\
\hline & WIN55,212 & CB1 & $\downarrow \downarrow$ & - & \\
\hline & HU308 & CB2 & $\uparrow \downarrow$ & $\uparrow$ & - \\
\hline & JWH133 & CB2 & $\uparrow \downarrow \downarrow$ & $\downarrow \downarrow \uparrow$ & \\
\hline & JWH139 & CB2 & $\downarrow$ & - & \\
\hline & JWH015 & CB2 & $\downarrow \downarrow$ & $\downarrow$ & $\downarrow$ \\
\hline & AM1241 & CB2 & $\downarrow$ & $\downarrow$ & \\
\hline & Lysophosphatidyl inositol & GPR55 & - & - & - \\
\hline & $0-1602$ & GPR55 & - & - & \\
\hline \multirow[t]{5}{*}{ Antagonists } & AM630 & CB2>CB1/GPR55 & - & $\downarrow$ & \\
\hline & SR144528 & $\mathrm{CB} 2>\mathrm{CB} 1$ & - & - & \\
\hline & AM251 & CB1>CB2/GPR55 & - & - & \\
\hline & SR141716A & $\mathrm{CB} 1>\mathrm{CB} 2$ & - & - & \\
\hline & Cannabidiol & GPR55 & $\downarrow \downarrow$ & - & $\downarrow$ \\
\hline
\end{tabular}

Abbreviations: CB1, cannabinoid type 1 receptor; CB2, cannabinoid type 2 receptor; GPR55, G protein-coupled receptor 55; TRPV1, transient receptor potential vanilloid type 1. Tm., tumor cell. $\uparrow$, increase; $\downarrow$, decrease; -, non tested. Black and red arrows denote in vitro and in vivo data, respectively.

of cancer metastasis (Berx et al., 1998; Jezierska and Motyl, 2009; Niu et al., 2015).

Lozano-Ondoua et al. noted that the $\mathrm{CB} 2$ receptor agonist reduced the degree of tumor burden within the intramedullary cavity of the femoris and produced anti-progressive effects of the tumor in vivo (Lozano-Ondoua et al., 2013).

Lozano-Ondoua et al. (2010) showed that CB2 receptor agonists could attenuate sarcoma-induced pain, reduce cancer-induced osteolytic destruction, and prevent the occurrence of pathological bone fracture. $\mathrm{CB} 1$ and $\mathrm{CB} 2$ were found to be associated with mediating ligands and molecular mechanisms associated with synthesis, transport and metabolism with potential effects of reducing complications of primary bone tumors. Especially, CB1 and CB2 agonists reduced bone cancer pain in animal models (Curto-Reyes et al., 2010; Kawamata et al., 2010). Therefore, this approach may be applied as analgesic treatment in patients with Bone tumors. The role of cannabinoid receptor ligands in regulating tumor cells and bone diseases in vitro and in vivo are shown in Table 2.

\section{Bone Fractures}

Bone fractures are highly prevalent, involving prolonged immobilization and discomfort. Some researchers have found that CBRs trigger bone formation and strengthen the bridge that connects broken bones (Kogan et al., 2015). Kogan et al. (2015) reported that the major non-psychoactive cannabis constituent CBD enhanced the biomechanical properties of rat mid-femoral fracture healing. Micro-computed tomography $(\mu \mathrm{CT})$ showed that the fracture callus size was transiently reduced by either CBD or THC 4 weeks after fracture but reached control level after 6 and 8 weeks. The callus material density was unaffected by $\mathrm{CBD}$ and/or THC. In contrast, CBD stimulated mRNA expression of Plod 1 in primary $\mathrm{OB}$ cultures to encode an enzyme that catalyzes lysine hydroxylation, which in turn

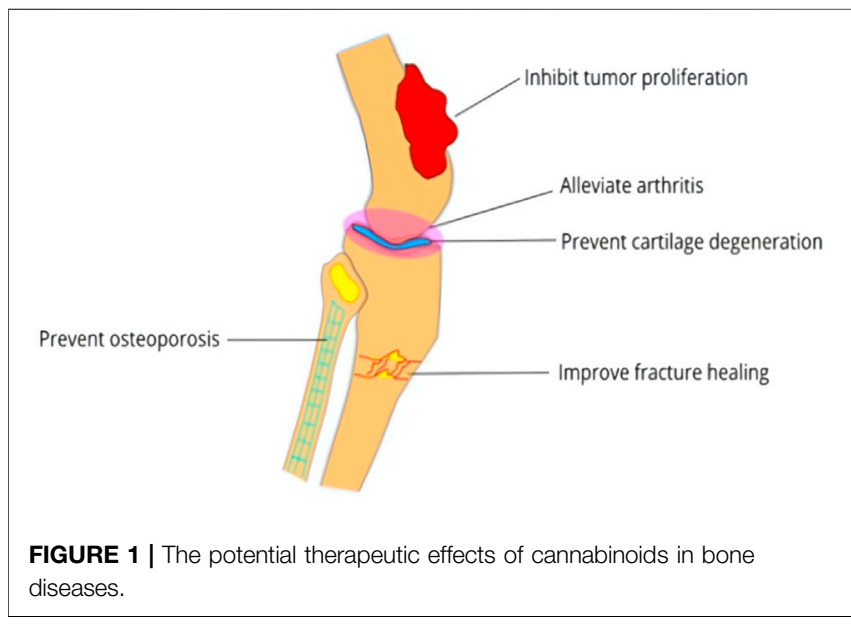

was involved in collagen cross-linking and stabilization. These data show that CBD can improve fracture healing and plays a critical mechanical role of collagen cross-linked enzymes. The bones of rats treated with CBD alone not only healed faster but the previous fracture was less likely to break in the future because of a strengthened fracture callus. Therefore, CBD provides research directions for the treatment and prognosis of fractures.

Bab et al. (2011) showed that fatty acid amides (FAAs) assisted in the process of bone metabolism by interacting with CBRs. FAAs are important because they are broken down by a particular enzyme (FAAH) that is blocked by CBD. For quite some time, CBD was known to inhibit FAAH, knowing that it could prevent the enzyme from breaking down bone forming compounds. An effective function of bone anabolic-antiresorptive is shared by many skeletal FAAs. Inhibition of the FAA degrading enzyme (FAAH) may prove to be an effective therapeutic strategy for the treatment of bone fractures. 
In summary, CBs could alleviate the development of arthritis, prevent osteoporosis, inhibit bone tumor cell proliferation, reduce bone cancer pain and improve fracture healing (Figure 1).

\section{CONCLUSION}

Bones provide structural support and physical protection to our soft tissues and allow us to walk, eat, breed and carry out the life activities. The ECS has been shown to regulate bone metabolism. An eCB deficiency may affect the skeletal system. No CB compound has been approved for the treatment of bone diseases at present. However, the important skeletal actions of the ECS have prompted both preclinical researchers and industrial companies to explore the clinical therapeutic potential based on CBs in the treatment of various bone diseases.

Evidence indicates the potential role of the ECS in the treatment of bone diseases because of the multiple targets involved in the pathologic process of various bone conditions including $\mathrm{OP}, \mathrm{OA}$, bone tumors and bone fractures. However, there is currently limited research on the use of CBs in the treatment of bone diseases, and the evaluation of medicinal cannabis in humans remains in its infancy. The following work still need to be further explored.

Firstly, the effect of CBR regulation on bone tissue metabolism needs further investigation in details. As it is necessary to further study the regulatory mechanisms of eCBs on osteogenesis, bone loss, synovial inflammatory response and arthritis pain, comprehensive evaluations of in vitro and in vivo mechanisms and pharmacologicals should be performed on each member of the eCB family.

\section{REFERENCES}

Bab, I., Ofek, O., Tam, J., Rehnelt, J., and Zimmer, A. (2008). Endocannabinoids and the Regulation of Bone Metabolism. J. Neuroendocrinol 20, 69-74. doi:10.1111/j.1365-2826.2008.01675.x

Bab, I., Smoum, R., Bradshaw, H., and Mechoulam, R. (2011). Skeletal Lipidomics: Regulation of Bone Metabolism by Fatty Acid Amide Family. Br. J. Pharmacol. 163 (7), 1441-1446. doi:10.1111/j.1476-5381.2011.01474.x

Berx, G., Nollet, F., and van Roy, F. (1998). Dysregulation of the E-Cadherin/ catenin Complex by Irreversible Mutations in Human Carcinomas. Cell Adhes. Commun. 6 (null), 171-184. doi:10.3109/15419069809004474

Carnovali, M., Ottria, R., Pasqualetti, S., Banfi, G., Ciuffreda, P., and Mariotti, M. (2016). Effects of Bioactive Fatty Acid Amide Derivatives in Zebrafish Scale Model of Bone Metabolism and Disease. Pharmacol. Res. 104 (undefined), 1-8. doi:10.1016/j.phrs.2015.12.009

Curto-Reyes, V., Llames, S., Hidalgo, A., Menéndez, L., and Baamonde, A. (2010). Spinal and Peripheral Analgesic Effects of the CB2 Cannabinoid Receptor Agonist AM1241 in Two Models of Bone Cancer-Induced Pain. Br. J. Pharmacol. 160 (3), 561-573. doi:10.1111/j.1476-5381.2009.00629.x

Devane, W. A., Dysarz, F. A., Johnson, M. R., Melvin, L. S., and Howlett, A. C. (1988). Determination and Characterization of a Cannabinoid Receptor in Rat Brain. Mol. Pharmacol. 34 (5), 605-613.

Devane, W. A., Hanus, L., Breuer, A., Pertwee, R. G., Stevenson, L. A., Griffin, G., et al. (1992). Isolation and Structure of a Brain Constituent that Binds to the Cannabinoid Receptor. Science 258 (5090), 1946-1949. doi:10.1126/science.1470919

Di Marzo, V., and Petrosino, S. (2007). Endocannabinoids and the Regulation of Their Levels in Health and Disease. Curr. Opin. Lipidol. 18 (2), 129-140. doi:10.1097/MOL.0b013e32803dbdec
Secondly, to ensure clinical applicability of CBs, it is necessary to explore new ways to improve the therapeutic effects of $\mathrm{CBs}$ and reduce their neurological adverse effects, such as synthesizing new $\mathrm{CB}$ drugs and using $\mathrm{CB}$ hydrolase inhibitors to increase endogenous levels of CBs. Finally, further investigations on the function of the ECS and its role in bone diseases are required to provide a solid foundation for the evolution and refinement of cannabis-based medicines. Comprehensive evaluations through high-quality randomized controlled trials (RCTs) are also required to identify the true clinical efficacy and long-term risks associated with CB therapy.

The ECS plays a role in maintaining the bones strength and combating bone diseases, and holds promise as a novel drug for bone disease treatment.

\section{AUTHOR CONTRIBUTIONS}

YX designed the study and AT prepared the first draft of the paper. SP was responsible for figure and table. JZ modified the study. He is guarantor. All authors revised the paper critically for intellectual content and approved the final version. All authors agree to be accountable for the work and to ensure that any questions relating to the accuracy and integrity of the paper are investigated and properly resolved.

\section{FUNDING}

This work was supported by the National Natural Science Foundation of China (Grant No. 81960200 and 82160184).

Di Marzo, V. (2008). Targeting the Endocannabinoid System: to Enhance or Reduce? Nat. Rev. Drug Discov. 7, 438-455. doi:10.1038/nrd2553

Dou, Z.-j., Gao, X.-L., Jia, Y.-l., Chen, J., Yang, J.-J., Chen, Y., et al. (2020). CB1 Receptor Antagonist Rimonabant Protects against Chronic Intermittent Hypoxia-Induced Bone Metabolism Disorder and Destruction in Rats. Sleep Breath 24, 1441-1449. doi:10.1007/s11325-019-02009-9

Dunn, S. L., Wilkinson, J. M., Crawford, A., Bunning, R. A. D., and Le Maitre, C. L. (2016). Expression of Cannabinoid Receptors in Human Osteoarthritic Cartilage: Implications for Future Therapies. Cannabis Cannabinoid Res. 1 (1), 3-15. doi:10.1089/can.2015.0001

Dunn, S. L., Wilkinson, J. M., Crawford, A., Le Maitre, C. L., and Bunning, R. A. (2012). Cannabinoids: Novel Therapies for Arthritis? Future Med. Chem. 4 (6), 713-725. doi:10.4155/fmc. 12.20

Ehrenkranz, J., and Levine, M. A. (2019). Bones and Joints: The Effects of Cannabinoids on the Skeleton. J. Clin. Endocrinol. Metab. 104 (10), 4683-4694. doi:10.1210/jc.2019-00665

Frei, R. B., Luschnig, P., Parzmair, G. P., Peinhaupt, M., Schranz, S., Fauland, A., et al. (2016). Cannabinoid Receptor 2 Augments Eosinophil Responsiveness and Aggravates Allergen-Induced Pulmonary Inflammation in Mice. Allergy 71 (7), 944-956. doi:10.1111/all.12858

Gaoni, Y., and Mechoulam, R. (1964). Isolation, Structure, and Partial Synthesis of an Active Constituent of Hashish. J. Am. Chem. Soc. 86, 1646-1647. doi:10.1021/ja01062a046

Ghilardi, J. R., Röhrich, H., Lindsay, T. H., Sevcik, M. A., Schwei, M. J., Kubota, K., et al. (2005). Selective Blockade of the Capsaicin Receptor TRPV1 Attenuates Bone Cancer Pain. J. Neurosci. 25 (12), 3126-3131. doi:10.1523/ JNEUROSCI.3815-04.2005

Grinspoon, J. (1993). “Cannabis as a Medicine," in Marijuana: The Forbidden Medicine (New Haven: Yale University Press), 67-81. 
Grotenhermen, F., and Müller-Vahl, K. (2012). The Therapeutic Potential of Cannabis and Cannabinoids. Dtsch Arztebl Int. 109 (null), 495-501. doi:10.3238/arztebl.2012.0495

Gui, H., Liu, X., Wang, Z. W., He, D. Y., Su, D. F., and Dai, S. M. (2014). Expression of Cannabinoid Receptor 2 and its Inhibitory Effects on Synovial Fibroblasts in Rheumatoid Arthritis. Rheumatology (Oxford) 53 (5), 802-809. doi:10.1093/ rheumatology/ket447

Guidetti, R., Astles, P. C., Sanderson, A. J., Hollinshead, S. P., Johnson, M. P., and Chambers, M. G. (2014). The SAR Development of Substituted Purine Derivatives as Selective CB2 Agonists for the Treatment of Chronic Pain. Bioorg. Med. Chem. Lett. 24 (24), 5572-5575. doi:10.1016/j.bmcl.2014.11.006

Gustafsson, K., Wang, X., Severa, D., Eriksson, M., Kimby, E., Christensson, B., et al. (2008). Expression of Cannabinoid Receptors Type 1 and Type 2 in Nonhodgkin Lymphoma: Growth Inhibition by Receptor Activation. Int. J. Cancer 123 (5), 1025-1033. doi:10.1002/ijc.23584

Hutchins, H. L., Li, Y., Hannon, K., and Watkins, B. A. (2011). Eicosapentaenoic Acid Decreases Expression of Anandamide Synthesis Enzyme and Cannabinoid Receptor 2 in Osteoblast-like Cells. J. Nutr. Biochem. 22 (2), 195-200. doi:10.1016/j.jnutbio.2010.06.001

Idris, A. I., Landao-Bassonga, E., and Ralston, S. H. (2010). The TRPV1 Ion Channel Antagonist Capsazepine Inhibits Osteoclast and Osteoblast Differentiation In Vitro and Ovariectomy Induced Bone Loss In Vivo. Bone 46 (4), 1089-1099. doi:10.1016/j.bone.2010.01.368

Idris, A. I., and Ralston, S. H. (2010). Cannabinoids and Bone: Friend or Foe? Calcif. Tissue Int. 87 (4), 285-297. doi:10.1007/s00223-010-9378-8

Idris, A. I., Sophocleous, A., Landao-Bassonga, E., Canals, M., Milligan, G., Baker, D., et al. (2009). Cannabinoid Receptor Type 1 Protects against Age-Related Osteoporosis by Regulating Osteoblast and Adipocyte Differentiation in Marrow Stromal Cells. Cell Metab 10 (2), 139-147. doi:10.1016/ j.cmet.2009.07.006

Idris, A. I., van 't Hof, R. J., Greig, I. R., Ridge, S. A., Baker, D., Ross, R. A., et al. (2005). Regulation of Bone Mass, Bone Loss and Osteoclast Activity by Cannabinoid Receptors. Nat. Med. 11 (7), 774-779. doi:10.1038/nm1255

Jezierska, A., and Motyl, T. (2009). Matrix Metalloproteinase-2 Involvement in Breast Cancer Progression: a Mini-Review. Med. Sci. Monit. 15 (2), RA32-40. doi:10.1016/j.mehy.2008.08.012

Jiang, S., Zagozdzon, R., Jorda, M. A., Parmar, K., Fu, Y., Williams, J. S., et al. (2010). Endocannabinoids Are Expressed in Bone Marrow Stromal Niches and Play a Role in Interactions of Hematopoietic Stem and Progenitor Cells with the Bone Marrow Microenvironment. J. Biol. Chem. 285 (46), 35471-35478. doi:10.1074/jbc.M110.144758

Joshi, N., and Onaivi, E. S. (2019). Endocannabinoid System Components: Overview and Tissue Distribution. Adv. Exp. Med. Biol. 1162 (undefined), 1-12. doi:10.1007/978-3-030-21737-2_1

Karsdal, M. A., Bay-Jensen, A. C., Lories, R. J., Abramson, S., Spector, T., Pastoureau, P., et al. (2014). The Coupling of Bone and Cartilage Turnover in Osteoarthritis: Opportunities for Bone Antiresorptives and Anabolics as Potential Treatments? Ann. Rheum. Dis. 73 (2), 336-348. doi:10.1136/ annrheumdis-2013-204111

Kawamata, T., Niiyama, Y., Yamamoto, J., and Furuse, S. (2010). Reduction of Bone Cancer Pain by CB1 Activation and TRPV1 Inhibition. J. Anesth. 24 (2), 328-332. doi:10.1007/s00540-010-0919-0

Kogan, N. M., Melamed, E., Wasserman, E., Raphael, B., Breuer, A., Stok, K. S., et al. (2015). Cannabidiol, a Major Non-psychotropic Cannabis Constituent Enhances Fracture Healing and Stimulates Lysyl Hydroxylase Activity in Osteoblasts. J. Bone Miner Res. 30, 1905-1913. doi:10.1002/jbmr.2513

Liu, X., Xu, Y., Chen, S., Tan, Z., Xiong, K., Ye, Y., et al. (2014). Rescue of Proinflammatory Cytokine-Inhibited Chondrogenesis by the Antiarthritic Effect of Melatonin in Synovium Mesenchymal Stem Cells via Suppression of Reactive Oxygen Species and Matrix Metalloproteinases. Free Radic. Biol. Med. 68 (undefined), 234-246. doi:10.1016/j.freeradbiomed.2013.12.012

Lowin, T., Schneider, M., and Pongratz, G. (2019). Joints for Joints: Cannabinoids in the Treatment of Rheumatoid Arthritis. Curr. Opin. Rheumatol. 31 (3), 271-278. doi:10.1097/BOR.0000000000000590

Lozano-Ondoua, A. N., Hanlon, K. E., Symons-Liguori, A. M., Largent-Milnes, T. M., Havelin, J. J., Ferland, H. L., et al. (2013). Disease Modification of Breast Cancer-Induced Bone Remodeling by Cannabinoid 2 Receptor Agonists. J. Bone Miner Res. 28 (1), 92-107. doi:10.1002/jbmr.1732
Lozano-Ondoua, A. N., Wright, C., Vardanyan, A., King, T., Largent-Milnes, T. M., Jimenez-Andrade, J. M., et al. (2010). A Cannabinoid 2 Receptor Agonist Attenuates Bone Cancer-Induced Pain and Bone Loss. Life Sci. 86 (null), 646-653. doi:10.1016/j.lfs.2010.02.014

Maccarrone, M., Bab, I., Bíró, T., Cabral, G. A., Dey, S. K., Di Marzo, V., et al. (2015). Endocannabinoid Signaling at the Periphery: 50 Years after THC. Trends Pharmacol. Sci. 36 (5), 277-296. doi:10.1016/j.tips.2015.02.008

Malfait, A. M., Gallily, R., Sumariwalla, P. F., Malik, A. S., Andreakos, E., Mechoulam, R., et al. (2000). The Nonpsychoactive Cannabis Constituent Cannabidiol Is an Oral Anti-arthritic Therapeutic in Murine CollagenInduced Arthritis. Proc. Natl. Acad. Sci. U S A. 97 (17), 9561-9566. doi:10.1073/pnas.160105897

Marino, S., de Ridder, D., Bishop, R. T., Renema, N., Ponzetti, M., Sophocleous, A., et al. (2019). Paradoxical Effects of JZL184, an Inhibitor of Monoacylglycerol Lipase, on Bone Remodelling in Healthy and Cancer-Bearing Mice. EBioMedicine 44, 452-466. doi:10.1016/j.ebiom.2019.05.048

Marino, S., and Idris, A. I. (2017). Emerging Therapeutic Targets in Cancer Induced Bone Disease: A Focus on the Peripheral Type 2 Cannabinoid Receptor. Pharmacol. Res. 119 (undefined), 391-403. doi:10.1016/ j.phrs.2017.02.023

Mbvundula, E. C., Bunning, R. A., and Rainsford, K. D. (2006). Arthritis and Cannabinoids: HU-210 and Win-55,212-2 Prevent IL-1alpha-induced Matrix Degradation in Bovine Articular Chondrocytes In-Vitro. J. Pharm. Pharmacol. 58 (3), 351-358. doi:10.1211/jpp.58.3.0009

McPartland, J. M., Matias, I., Di Marzo, V., and Glass, M. (2006). Evolutionary Origins of the Endocannabinoid System. Gene 370 (undefined), 64-74. doi:10.1016/j.gene.2005.11.004

Mechoulam, R., Ben-Shabat, S., Hanus, L., Ligumsky, M., Kaminski, N. E., Schatz, A. R., et al. (1995). Identification of an Endogenous 2-monoglyceride, Present in Canine Gut, that Binds to Cannabinoid Receptors. Biochem. Pharmacol. 50 (1), 83-90. doi:10.1016/0006-2952(95)00109-d

Mechoulam, R. (1986). "The Pharmacohistory of Cannabis Sativa," in Cannabinoids as Therapeutic Agents (Roca Raton: CRC Press), 1-19.

Munro, S., Thomas, K. L., and Abu-Shaar, M. (1993). Molecular Characterization of a Peripheral Receptor for Cannabinoids. Nature 365, 61-65. doi:10.1038/ $365061 \mathrm{a} 0$

Niu, F., Zhao, S., Xu, C. Y., Sha, H., Bi, G. B., Ye, L., et al. (2015). Potentiation of the Antitumor Activity of Adriamycin against Osteosarcoma by Cannabinoid WIN-55,212-2. Oncol. Lett. 10 (4), 2415-2421. doi:10.3892/ol.2015.3525

Ofek, O., Karsak, M., Leclerc, N., Fogel, M., Frenkel, B., Wright, K., et al. (2006). Peripheral Cannabinoid Receptor, CB2, Regulates Bone Mass. Proc. Natl. Acad. Sci. U S A. 103 (3), 696-701. doi:10.1073/pnas.0504187103

Ossola, C. A., Surkin, P. N., Mohn, C. E., Elverdin, J. C., and Fernández-Solari, J. (2016). Anti-Inflammatory and Osteoprotective Effects of Cannabinoid-2 Receptor Agonist HU-308 in a Rat Model of Lipopolysaccharide-Induced Periodontitis. J. Periodontol. 87, 725-734. doi:10.1902/jop.2016.150612

Pertwee, R. G. (2005). Pharmacological Actions of Cannabinoids," in Handb Exp. Pharmacol., Chap. 1, 1-51. doi:10.1007/3-540-26573-2_1

Pertwee, R. G., Howlett, A. C., Abood, M. E., Alexander, S. P., Di Marzo, V., Elphick, M. R., et al. (2010). International Union of Basic and Clinical Pharmacology. LXXIX. Cannabinoid Receptors and Their Ligands: beyond $\mathrm{CB}_{1}$ and $\mathrm{CB}_{2}$. Pharmacol. Rev. 62 (4), 588-631. doi:10.1124/pr.110.003004

Pertwee, R. G. (2010). Receptors and Channels Targeted by Synthetic Cannabinoid Receptor Agonists and Antagonists. Curr. Med. Chem. 17 (14), 1360-1381. doi:10.2174/092986710790980050

Pertwee, R. G., and Ross, R. A. (2002). Cannabinoid Receptors and Their Ligands. Prostaglandins Leukot. Essent. Fatty Acids 66, 101-121. doi:10.1054/ plef.2001.0341

Preet, A., Ganju, R. K., and Groopman, J. E. (2008). Delta9-Tetrahydrocannabinol Inhibits Epithelial Growth Factor-Induced Lung Cancer Cell Migration In Vitro as Well as its Growth and Metastasis In Vivo. Oncogene 27 (3), 339-346. doi:10.1038/sj.onc.1210641

Qamri, Z., Preet, A., Nasser, M. W., Bass, C. E., Leone, G., Barsky, S. H., et al. (2009). Synthetic Cannabinoid Receptor Agonists Inhibit Tumor Growth and Metastasis of Breast Cancer. Mol. Cancer Ther. 8 (11), 3117-3129. doi:10.1158/ 1535-7163.MCT-09-0448

Richardson, D., Pearson, R. G., Kurian, N., Latif, M. L., Garle, M. J., Barrett, D. A., et al. (2008). Characterisation of the Cannabinoid Receptor System in Synovial 
Tissue and Fluid in Patients with Osteoarthritis and Rheumatoid Arthritis. Arthritis Res. Ther. 10 (2), R43. doi:10.1186/ar2401

Robson, P. J. (2014). Therapeutic Potential of Cannabinoid Medicines. Drug Test. Anal. 6 (null), 24-30. doi:10.1002/dta.1529

Rossi, F., Bellini, G., Luongo, L., Torella, M., Mancusi, S., De Petrocellis, L., et al. (2011). The Endovanilloid/endocannabinoid System: a New Potential Target for Osteoporosis Therapy. Bone 48 (5), 997-1007. doi:10.1016/ j.bone.2011.01.001

Rossi, F., Siniscalco, D., Luongo, L., De Petrocellis, L., Bellini, G., Petrosino, S., et al. (2009). The Endovanilloid/endocannabinoid System in Human Osteoclasts: Possible Involvement in Bone Formation and Resorption. Bone 44 (3), 476-484. doi:10.1016/j.bone.2008.10.056

Rossi, F., Tortora, C., Punzo, F., Bellini, G., Argenziano, M., Di Paola, A., et al. (2019). The Endocannabinoid/Endovanilloid System in Bone: From Osteoporosis to Osteosarcoma. Int. J. Mol. Sci. 20 (8). doi:10.3390/ ijms20081919

Schuelert, N., Johnson, M. P., Oskins, J. L., Jassal, K., Chambers, M. G., and McDougall, J. J. (2011). Local Application of the Endocannabinoid Hydrolysis Inhibitor URB597 Reduces Nociception in Spontaneous and Chemically Induced Models of Osteoarthritis. Pain 152 (5), 975-981. doi:10.1016/ j.pain.2010.11.025

Silver Robert, J. (2019). The Endocannabinoid System of Animals. Animals (Basel) 9, 686. doi:10.3390/ani9090686

Smoum, R., Baraghithy, S., Chourasia, M., Breuer, A., Mussai, N., Kogan, N. M., et al. (2015). CB2 Cannabinoid Receptor Agonist Enantiomers HU-433 and HU-308: An Inverse Relationship between Binding Affinity and Biological Potency. Proc. Natl. Acad. Sci. U S A. 112 (28), 8774-8779. doi:10.1073/ pnas. 1503395112

Sophocleous, A., Börjesson, A. E., Salter, D. M., and Ralston, S. H. (2015). The Type 2 Cannabinoid Receptor Regulates Susceptibility to Osteoarthritis in Mice. Osteoarthritis Cartilage 23 (9), 1586-1594. doi:10.1016/j.joca.2015.04.020

Sophocleous, A., Marino, S., Kabir, D., Ralston, S. H., and Idris, A. I. (2017). Combined Deficiency of the Cnr1 and Cnr2 Receptors Protects against AgeRelated Bone Loss by Osteoclast Inhibition. Aging Cell 16 (5), 1051-1061. doi:10.1111/acel.12638

Sumariwalla, P. F., Gallily, R., Tchilibon, S., Fride, E., Mechoulam, R., and Feldmann, M. (2004). A Novel Synthetic, Nonpsychoactive Cannabinoid Acid (HU-320) with Antiinflammatory Properties in Murine CollagenInduced Arthritis. Arthritis Rheum. 50 (3), 985-998. doi:10.1002/art.20050

Sun, R., Zhang, B., Chen, L., and Sun, J. (2014). Role of Nuclear Factor of Activated T Cells 1 in the Pathogenesis of Osteoarthritis. Exp. Ther. Med. 7 (1), 195-198. doi:10.3892/etm.2013.1390

Tam, J., Ofek, O., Fride, E., Ledent, C., Gabet, Y., Zimmer, A., et al. (2006). Involvement of Neuronal Cannabinoid Receptor CB1 in Regulation of Bone Mass and Bone Remodeling. Mol. Pharmacol. 70 (3), 786-792. doi:10.1124/ mol.106.026435
Tam, J., Trembovler, V., Di Marzo, V., Petrosino, S., Leo, G., Alexandrovich, A. et al. (2008). The Cannabinoid CB1 Receptor Regulates Bone Formation by Modulating Adrenergic Signaling. FASEB J. 22 (1), 285-294. doi:10.1096/fj.06$7957 \mathrm{com}$

Whyte, L. S., Ford, L., Ridge, S. A., Cameron, G. A., Rogers, M. J., and Ross, R. A. (2012). Cannabinoids and Bone: Endocannabinoids Modulate Human Osteoclast Function In Vitro. Br. J. Pharmacol. 165 (8), 2584-2597. doi:10.1111/j.1476-5381.2011.01519.x

Whyte, L. S., Ryberg, E., Sims, N. A., Ridge, S. A., Mackie, K., Greasley, P. J., et al. (2009). The Putative Cannabinoid Receptor GPR55 Affects Osteoclast Function In Vitro and Bone Mass In Vivo. Proc. Natl. Acad. Sci. U S A. 106 (38), 16511-16516. doi:10.1073/pnas.0902743106

Yan, W., Cao, Y., Yang, H., Han, N., Zhu, X., Fan, Z., et al. (2019). CB1 Enhanced the Osteo/dentinogenic Differentiation Ability of Periodontal Ligament Stem Cells via P38 MAPK and JNK in an Inflammatory Environment. Cell Prolif 52, e12691. doi:10.1111/cpr.12691

Yang, L., Li, F. F., Han, Y. C., Jia, B., and Ding, Y. (2015). Cannabinoid Receptor CB2 Is Involved in Tetrahydrocannabinol-Induced Anti-inflammation against Lipopolysaccharide in MG-63 Cells. Mediators Inflamm. 2015 (undefined), 362126. doi:10.1155/2015/362126

Yang, S., Dubé, C. E., Eaton, C. B., McAlindon, T. E., and Lapane, K. L. (2013). Longitudinal Use of Complementary and Alternative Medicine Among Older Adults with Radiographic Knee Osteoarthritis. Clin. Ther. 35 (11), 1690-1702. doi:10.1016/j.clinthera.2013.09.022

Zhang, M., Shi, X., Wu, J., Wang, Y., Lin, J., Zhao, Y., et al. (2019). CoCl2 Induced Hypoxia Enhances Osteogenesis of Rat Bone Marrow Mesenchymal Stem Cells through Cannabinoid Receptor 2. Arch. Oral Biol. 108, 104525. doi:10.1016/ j.archoralbio.2019.104525

Conflict of Interest: The authors declare that the research was conducted in the absence of any commercial or financial relationships that could be construed as a potential conflict of interest.

Publisher's Note: All claims expressed in this article are solely those of the authors and do not necessarily represent those of their affiliated organizations, or those of the publisher, the editors and the reviewers. Any product that may be evaluated in this article, or claim that may be made by its manufacturer, is not guaranteed or endorsed by the publisher.

Copyright (c) 2022 Xin, Tang, Pan and Zhang. This is an open-access article distributed under the terms of the Creative Commons Attribution License (CC $B Y)$. The use, distribution or reproduction in other forums is permitted, provided the original author(s) and the copyright owner(s) are credited and that the original publication in this journal is cited, in accordance with accepted academic practice. No use, distribution or reproduction is permitted which does not comply with these terms. 